\title{
Influence of maturity stages and variety on viscoelastic properties and mechanical toughness of the strawberries
}

\section{Sergiu Pădureţ}

\section{Faculty of Food Engineering, "Stefan cel Mare" University of Suceava, Suceava, Romania}

\section{Keywords:}

Burger model

Creep

Retardation

Strawberries

Strain

Article history:

Received 16.03.2019

Received in revised form 18.06.2019

Accepted 28.11.2019

\section{Corresponding author:}

SergiuPădureţ

E-mail:

sergiu.paduret@fia.usv.ro

DOI: $10.24263 / 2304$

974X-2019-8-4-5

\section{Abstract}

Introduction. This study aims to determine the influence of maturity stages and variety on the strawberries viscoelastic properties and to evaluate their mechanical toughness.

Materials and methods. The fresh strawberry samples (Vibrant, Elsanta and Magic variety) were subjected to a creep test and the Burger model with four Kelvin Voigt elements was used to determine the viscoelastic parameters. The strawberry samples were divided on three maturity stages: almost ripe (S1), ripe (S2) and overripe (S3).

Results and discussion. The strawberries samples were analyzed in terms of moisture content, soluble substances concentration, $\mathrm{pH}$ and total acidity. The moisture content ranged between 87.38 and $89.67 \%$, the overripe maturity stage (S3) showing higher values of moisture compared to nearly ripe ones $(\mathrm{S} 1), \mathrm{p}<0.05$. The highest concentration of soluble substances was recorded by Elsanta variety overripe maturity stage and followed by Magic (11.91) and Vibrant (11.57) varieties.

The instantaneous elastic strain of strawberries ranged between $1.057-3.135 \mathrm{~mm}$ and the retardation time, which is correlated with storage period, varies from 10.92 to $140.83 \mathrm{~s}$. The Pearson correlation matrix between physicochemical (moisture content, Brix concentration, $\mathrm{pH}$ and total acidity) and viscoelastic parameters (retarded and instantaneous elastic strain, retardation time, viscous strain, creep strain and area under the creep curves) highlighted a significant positive correlation between retarded elastic strain $(\varepsilon 2)$ and the creep strain $(\mathrm{p}<0.01)$.

Conclusions. The Vibrant strawberry variety had the highest resistance to mechanical impact and also a high mechanical resistance to compression due to the fact that showed the lowest values of instantaneous and retarded elastic strain 


\section{Introduction}

Strawberries (Fragaria x ananassa Duch.) are fragile, nonclimacteric fruits, consumed by worldwide people due to the nutrients presence (dietary fibers, vitamin $\mathrm{C}$, sugars, organic acids and minerals), bioactive compounds (phenols, anthocyanins) and for their organoleptic characteristics including texture properties $[1,2]$.

According to Kim, 2013, [3] strawberries have an initial growing and enlarging stage followed by a maturation stage. The ripening process of strawberries stops when the fruits are harvested, this biochemical process being a very complex one influenced by the hormones, pigments synthesis, the sugars metabolism and their action; thus the ripening process changes the fruits color, aroma, flavor and texture $[4,5]$.

Over the years a large number of strawberry varieties have been created by the breeding programs over the world, in Romania the most cultivated varieties were: Premial, Elsanta, Magic, Senga Sengana, Elegance, Real, Elsignore, Darselect; on an area of about 2,500 ha and with a production of approximately $9 \mathrm{t} / \mathrm{ha}[6]$.

A major aspect of strawberry fruits it is represented by their firmness, which is the result of both the fruit pulp firmness and fruit skin strength; the information about strawberries mechanical properties being of great importance. The firmness measurement of strawberries is valuable in quality assurance, ripening evaluation, toughness damage evaluation during handling or differences between varieties [7].

The fruits mechanical properties (firmness or toughness) are measured most commonly by various types of penetrometers (Magness Taylor test), which are less acceptable for softer fruits such as strawberries [8].

A relatively simple test for viscoelastic properties evaluation of food products and to obtain a rheological model is the creep test, which implies a constant stress application on a sample and the deformation or strain is measured as a function of time $[9,10]$.

The viscoelastic properties measurements by rheological tests were applied for: apples [11], frankfurters [12], potato [13], bread dough [14]and gels [15]. To date no other study related to the viscoelastic properties of strawberries has been reported.

Therefore, the objective of this study is to evaluate the viscoelastic properties and quality characteristics of three strawberry varieties based on compression creep test and Burger mechanical model.

\section{Materials and methods}

Materials. The fresh strawberry samples were purchased from a local producer (Suceava, Romania) and they are of the Vibrant, Elsanta and Magic variety. Each strawberry variety was divided on three maturity stages: almost ripe (S1), ripe (S2) and overripe (S3), having about the same weight $(18 \pm 0.35 \mathrm{~g})$ and volume $\left(20 \pm 0.55 \mathrm{~cm}^{3}\right)$.

Physicochemical parameters. The soluble substances concentration ( $\left.{ }^{\circ} \mathrm{Brix}\right)$ was measured with a Leica Mark II Plus refractometer, the moisture content was performed by oven method [16], the $\mathrm{pH}$ was measured using a Hach pH-meter (HQ11d), [17] and total acidity were determined too and express as $\mathrm{cm}^{3} \mathrm{NaOH} / 100 \mathrm{~g}$ sample [18].

Texture properties measurement. For strawberries texture properties (toughness) evaluation a creep test was performed using an electronic device (Mitutoyo, USA), [19], the stress force was held constant at $200 \mathrm{~g}$ and the stress time was $1200 \mathrm{~s}$. The compression probe 
was flat with a diameter of $70 \mathrm{~mm}$, larger than the cross-sectional area of the sample, thus eliminating the shear stress effect [20].

To determine the viscoelastic properties of strawberries samples, the strain versus time data (creep curves) were interpreted using Burger model with 4 KelvinVoigt elements (eq.1).

$$
\varepsilon(t)=\varepsilon_{1}+\varepsilon_{2}+\varepsilon_{3}=\frac{\sigma_{0}}{G_{0}}+\frac{\sigma_{0}}{G_{1}} \cdot\left(1-\exp \frac{-t}{\lambda_{\text {ret }}}\right)+\frac{\sigma_{0} \cdot t}{\mu_{0}}
$$

where $\varepsilon(\mathrm{t})$ represents the strain at retardation time $(\mathrm{t}), \varepsilon_{1}-$ the instantaneous elasticstrain, $\varepsilon_{2}$ -the retardedelastic strain, $\varepsilon_{3}$ - viscous strain, $\mathrm{G}_{0}$ - the instantaneous elastic modulus $(\mathrm{Pa}) ; \mathrm{G}_{1}$ - the retarded elastic modulus $(\mathrm{Pa}) ; \lambda_{\text {ret }}-$ the retardation time for the Kelvin part of the model (s); $\mu_{0}$ - the Newtonian viscosity of the free dashpot (Pa s) and $\sigma_{0}$ represents the constant stress $(\mathrm{Pa}),[21,22]$.

The Burger model shown in Fig. 1 is the series combination of a Kelvin-Voigt and Maxwell elements, dividing the creep curve into three parts: instantaneous deformation (Maxwell spring), viscoelastic deformation (Kelvin element) and viscous deformation (Maxwell dashpot) [11].

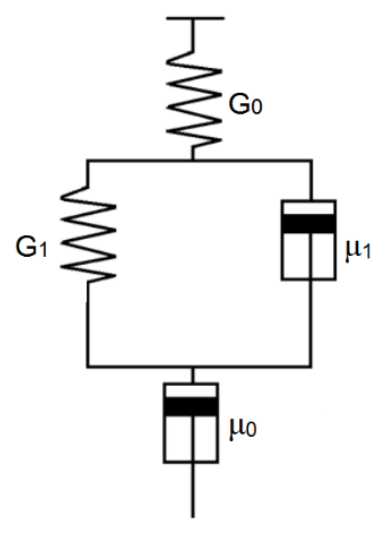

Figure 1. Burger model

As a measure of the Burger mechanical model's fit to the experimental data the coefficient of determination $\left(\mathrm{R}^{2}\right)$ and the absolute average deviation (AAD) were calculated by the following equations [23]:

$$
\begin{gathered}
R^{2}=1-\frac{\sum_{i=1}^{n}\left(Y_{C A L}-Y_{E X P}\right)^{2}}{\sum_{i=1}^{n}\left(Y_{E X P}-Y_{M E D I U}\right)^{2}} \\
A A D=\frac{1}{T} \cdot \sum_{i=1}^{n}\left|\frac{Y_{E X P}-Y_{C A L}}{Y_{E X P}}\right| \cdot 100
\end{gathered}
$$

where $\mathrm{Y}_{\mathrm{EXP}}$ and $\mathrm{Y}_{\mathrm{CAL}}$ are the experimental and calculated values data and $T$ is the number of the experimental run [24].

Statistical analysis. The results were subjected to one factor analysis of variance (ANOVA) by STATGRAPHICS CENTURION XVI, the statistical significance being set at $\alpha=0.05$. The Burger model predicted data was obtained by nonlinear regression analysis. Pearson correlation was performed by SPSS (SPSS Inc., Chicago, IL, USA) and Principal Component Analysis (PCA) by UNSCRAMBLER 9.7 (Trial Version). 


\section{Results and discussion}

\section{Physicochemical properties}

In Table 1 are presented the ANOVA results of physicochemical parameters of strawberry samples. The Vibrant, Elsanta and Magic strawberries varieties were analyzed in terms of moisture content, soluble substances concentration, $\mathrm{pH}$ and total acidity. The strawberries moisture content ranged between 87.38 and $89.67 \%$, the overripe maturity stage showing higher values of moisture compared to nearly ripe ones; the results of one factor analysis of variance ANOVA showed that the differences is statically significant at $\mathrm{p}<0.05$. The concentration of soluble substances express as ${ }^{\circ}$ Brix varies from 8.11 (almost ripe) to 13.89 (overripe), the highest concentration being recorded by Elsanta variety overripe maturity stage and followed by Magic (11.91) and Vibrant (11.57) varieties. The moisture and soluble substances contents being similar to those reported in other studies $[25,26]$.

ANOVA physicochemical parameters of strawberry samples

\begin{tabular}{|c|c|c|c|c|c|}
\hline \multicolumn{2}{|c|}{$\begin{array}{c}\text { Strawberry samples - } \\
\text { mean (SD) }\end{array}$} & \multirow{2}{*}{$\begin{array}{c}\begin{array}{c}\text { Moisture } \\
\text { [\%] }\end{array} \\
87.51^{\mathrm{b}} \\
(0.34)\end{array}$} & \multirow{2}{*}{$\begin{array}{c}{ }^{\circ} \text { Brix } \\
\text { concentration }\end{array}$} & \multirow{2}{*}{$\begin{array}{c}\text { pH } \\
3.88^{\mathrm{a}} \\
(0.09) \\
\end{array}$} & \multirow{2}{*}{ 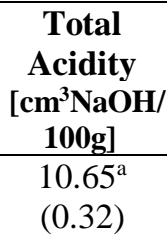 } \\
\hline \multirow{3}{*}{ Vibrant } & $\begin{array}{l}\text { Almost } \\
\text { ripe }\end{array}$ & & & & \\
\hline & Ripe & $\begin{array}{c}88.96^{\mathrm{ab}} \\
(0.41)\end{array}$ & $\begin{array}{c}9.21^{\mathrm{a}} \\
(0.12) \\
\end{array}$ & $\begin{array}{l}3.90^{\mathrm{a}} \\
(0.08)\end{array}$ & $\begin{array}{c}10.59^{\mathrm{ab}} \\
(0.25)\end{array}$ \\
\hline & $\begin{array}{c}\text { Over } \\
\text { ripe }\end{array}$ & $\begin{array}{l}89.67^{\mathrm{a}} \\
(0.25)\end{array}$ & $\begin{array}{l}11.57^{b} \\
(0.30)\end{array}$ & $\begin{array}{l}4.08^{\mathrm{a}} \\
(0.05) \\
\end{array}$ & $\begin{array}{l}9.37^{\mathrm{b}} \\
(0.54)\end{array}$ \\
\hline \multirow{3}{*}{ Elsanta } & $\begin{array}{c}\text { Almost } \\
\text { ripe }\end{array}$ & $\begin{array}{l}88.63^{b} \\
(0.31) \\
\end{array}$ & $\begin{array}{l}8.95^{\mathrm{a}} \\
(0.12) \\
\end{array}$ & $\begin{array}{l}3.80^{\mathrm{a}} \\
(0.08) \\
\end{array}$ & $\begin{array}{l}11.01^{\mathrm{a}} \\
(0.15)\end{array}$ \\
\hline & Ripe & $\begin{array}{l}89.01^{\mathrm{ab}} \\
(0.21)\end{array}$ & $\begin{array}{l}9.93^{\mathrm{a}} \\
(0.10) \\
\end{array}$ & $\begin{array}{l}3.85^{\mathrm{a}} \\
(0.11) \\
\end{array}$ & $\begin{array}{l}10.78^{\mathrm{ab}} \\
(0.19)\end{array}$ \\
\hline & Overripe & $\begin{array}{l}89.58^{a} \\
(0.22)\end{array}$ & $\begin{array}{l}13.89^{b} \\
(0.20)\end{array}$ & $\begin{array}{l}3.99^{a} \\
(0.05)\end{array}$ & $\begin{array}{l}9.29^{\mathrm{b}} \\
(0.21)\end{array}$ \\
\hline \multirow{3}{*}{ Magic } & $\begin{array}{l}\text { Almost } \\
\text { ripe }\end{array}$ & $\begin{array}{l}87.38^{b} \\
(0.11) \\
\end{array}$ & $\begin{array}{l}8.89^{\mathrm{a}} \\
(0.11) \\
\end{array}$ & $\begin{array}{l}3.92^{\mathrm{a}} \\
(0.05) \\
\end{array}$ & $\begin{array}{l}10.51^{\mathrm{a}} \\
(0.88)\end{array}$ \\
\hline & Ripe & $\begin{array}{c}87.90^{\mathrm{ab}} \\
(0.20)\end{array}$ & $\begin{array}{l}9.23^{\mathrm{a}} \\
(0.10)\end{array}$ & $\begin{array}{l}4.10^{\mathrm{a}} \\
(0.06)\end{array}$ & $\begin{array}{l}9.01^{\mathrm{ab}} \\
(0.10)\end{array}$ \\
\hline & Overripe & $\begin{array}{l}89.28^{\mathrm{a}} \\
(0.09)\end{array}$ & $\begin{array}{l}11.91^{\mathrm{b}} \\
(0.21)\end{array}$ & $\begin{array}{l}4.01^{\mathrm{a}} \\
(0.02) \\
\end{array}$ & $\begin{array}{l}9.32^{\mathrm{b}} \\
(0.56) \\
\end{array}$ \\
\hline \multicolumn{2}{|l|}{ F-Ratio } & 6.93 & 17.50 & 2.46 & 4.37 \\
\hline \multicolumn{2}{|c|}{$\mathrm{P}$ - value } & 0.027 & 0.003 & 0.166 & 0.067 \\
\hline
\end{tabular}

Note: NS - not significant ( $\mathrm{p}>0.05),{ }^{*} \mathrm{p}<0.05$, ** $\mathrm{p}<0.01, * * * \mathrm{p}<0.001$; Different lowercase letters in a column show significant differences between the groups $(\mathrm{p}<0.05)$. 
One way ANOVA analysis highlighted the soluble substancesdifference between thematurity stages of strawberries samples at a level of $\mathrm{p}<0.01$. The strawberries $\mathrm{pH}$ values were close to each other (3.80-4.10); the statistical differences being insignificant ( $p>0.05$ ). Total acidity content measurement is important in strawberries quality evaluation since less acidic strawberries are preferred to be consumed fresh, while more acidic strawberries are processed by food industry [27].

The total acidity of Vibrant, Elsanta and Magic varieties was between 9.29-11.01 $\mathrm{cm}^{3} \mathrm{NaOH} / 100 \mathrm{~g}$, decreasing with the strawberries ripening process; which is in agreement with the study of da Silva Pinto 2008, [28], who sustain also that the fruit acid content is consumed in the respiratory process.

\section{Texture properties measurement}

Mechanical properties evaluation is very important especially when it comes to fragile perishable food products susceptible to mechanical damage and it is also of great importance in measuring their viscoelastic properties. Strawberries are highly perishable fruits with a short shelf life due to the fact that they are predisposed to microbiological contamination and mechanical damage during harvesting, transport and storage; the fruit's resistance evaluation to mechanical shocks representing a very important aspect for both producers and consumers.

Figure 2 (a, b and c) presents the Vibrant, Elsanta and Magic strawberries toughness evaluation to mechanical stress by creep test and as we can see the strawberries deformation resistance depends on the fruit variety and also of the maturity stages. The most toughness strawberries to compression stress belong to the Vibrant variety followed by Elsanta and Magic. The creep curves of analyzed strawberries can be also characterized by two very important determinants - the strain and the area under the curve (W), this values being presented in Table 2 .

The strawberries strain range from $1.96 \mathrm{~mm}$ to $6.62 \mathrm{~mm}$, the greatest deformation being recorded by the Magic variety (5.79-6.62) which shows also the greatest area under the curve (75.65-81.45). In contrast with Magic variety, which shows a low resistance to deformation, the Vibrant variety strawberries have a greater resistance to deformation (1.96-2.67), being more resistant to mechanical shocks during the harvest and postharvest handling like sorting, packing, cleaning or to transport. As regarding the maturity stages, the overripe strawberries are softer than the ripe ones, the loss of deformation resistance being due to the ripening process, when the fruits turn redder, accumulate more sugars, the moisture content increases and lose some of their firmness [3].

\section{Strawberries viscoelastic parameters prediction using Burger model}

Another important aspect stated by Vergara 2018, [27] is that smaller strawberries (third category) have a higher resistance to deformation due to a more compact cellular arrangement. Also in Table 2 are presented the mathematical equations of Burger model, which were applied to describe the viscoelastic properties of analyzed strawberry samples; Figure 2 shows the Burger model's fit (predicted data) to the experimental data and it can be observed that the four elements mechanical model can be successfully used to predict the viscoelastic properties of strawberries samples. 

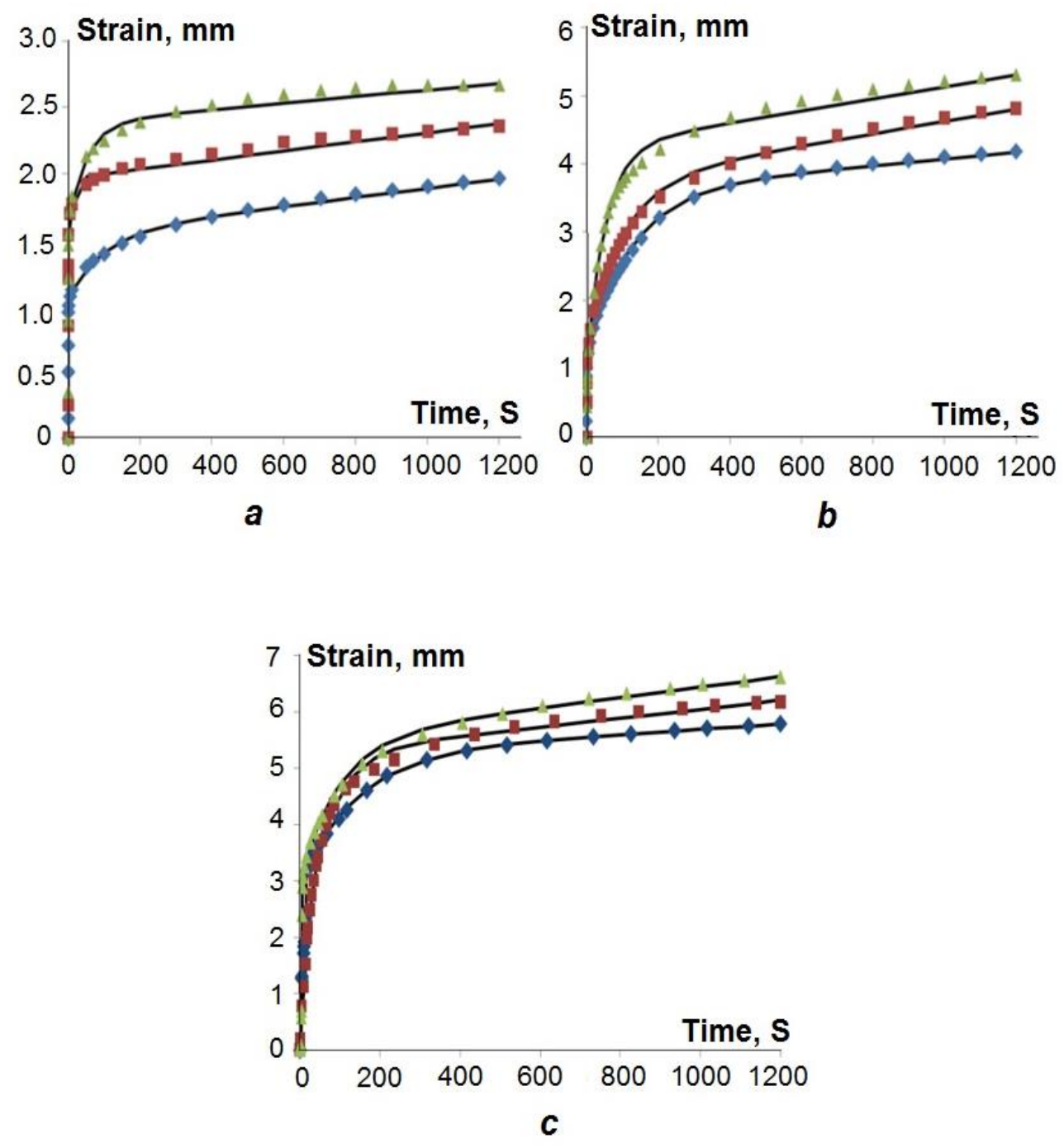

- S1 $\quad$ S2 2 S3 - Predicted

Figure 2. Creep curves of strawberry samples - experimental vs. predicted data: $a$-Vibrant, $b$-Elsanta, $c$-Magic.

S1 - almost ripe, $\mathbf{S 2}$ - ripe, $\mathbf{S 3}$ - overripe. 
Table 2

Equations of Burger mechanical model and the strawberries creep curves characteristics

\begin{tabular}{|c|c|c|c|c|c|c|c|}
\hline \multicolumn{2}{|c|}{ Sample } & \multicolumn{2}{|l|}{$\begin{array}{l}\text { Burger model with four } \\
\text { Kelvin Voigt elements }\end{array}$} & \multirow{2}{*}{$\begin{array}{c}\mathbf{R}^{2} \\
0.952\end{array}$} & \multirow{2}{*}{$\begin{array}{r}\text { AAD } \\
1.75\end{array}$} & \multirow{2}{*}{$\begin{array}{c}\begin{array}{c}\text { Strain } \\
{[\mathrm{mm}]}\end{array} \\
1.96\end{array}$} & \multirow{2}{*}{$\begin{array}{c}\begin{array}{c}\mathbf{W} \\
{[\mathbf{m m} \cdot \mathbf{m i n}]}\end{array} \\
26.58\end{array}$} \\
\hline \multirow{3}{*}{$\frac{\sqrt{2}}{\frac{5}{3}}$} & S1 & $\gamma=1.057+0.483 \cdot\left(1-\exp \frac{-t}{98.649}\right)$ & $+\frac{t}{2897.678}$ & & & & \\
\hline & S2 & $\gamma=1.374+0.588 \cdot\left(1-\exp \frac{-t}{10.920}\right)$ & $+\frac{t}{2906.185}$ & 0.926 & 2.35 & 2.36 & 35.78 \\
\hline & S3 & $\gamma=1.647+0.738 \cdot\left(1-\exp \frac{-t}{52.898}\right)$ & $+\frac{t}{4057.171}$ & 0.943 & 2.47 & 2.67 & 40.36 \\
\hline \multirow{3}{*}{$\frac{\sqrt{1}}{3}$} & S1 & $\gamma=1.108+2.473 \cdot\left(1-\exp \frac{-t}{120.032}\right.$ & $\int+\frac{t}{2025.271}$ & 0.982 & 2.95 & 4.18 & 50.11 \\
\hline & S2 & $\gamma=1.248+2.476 \cdot\left(1-\exp \frac{-t}{97.301}\right)$ & $+\frac{t}{1112.259}$ & 0.983 & 2.61 & 4.82 & 56.96 \\
\hline & S3 & $\gamma=1.321+3.113 \cdot\left(1-\exp \frac{-t}{56.056}\right)$ & $+\frac{t}{1336.073}$ & 0.971 & 4.26 & 5.30 & 66.60 \\
\hline \multirow{3}{*}{ 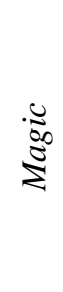 } & S1 & $\gamma=3.029+2.052 \cdot\left(1-\exp \frac{-t}{140.830}\right.$ & $\int+\frac{t}{2290.884}$ & 0.965 & 1.34 & 5.79 & 75.65 \\
\hline & S2 & $\gamma=3.114+2.168 \cdot\left(1-\exp \frac{-t}{66.543}\right)$ & $+\frac{t}{1282 . .330}$ & 0.944 & 1.31 & 6.18 & 77.93 \\
\hline & S3 & $\gamma=3.135+2.377 \cdot\left(1-\exp \frac{-t}{95.825}\right)$ & $+\frac{t}{1079.789}$ & 0.972 & 0.30 & 6.62 & 81.45 \\
\hline
\end{tabular}

S1-almost ripe, S2- ripe, S3- overripe, W- area under the creep curves.

The instantaneous elastic strain varied between $1.057 \mathrm{~mm}$ and $3.135 \mathrm{~mm}$, the highest values of this parameter being recorded by Magic variety; for Vibrant and Elsanta varieties it can be observed that this parameter presents smaller and close values which imply that these two varieties have a high resistance to mechanical impact. In addition the Elsanta strawberries had the highest values of retarded elastic strain $(2.473-3.113 \mathrm{~mm})$ predicted by the Burger model, followed by Magic variety $(2.052-2.377 \mathrm{~mm})$, while the Vibrant strawberries had the lowest values of retarded elastic strain $(0.483-0.738 \mathrm{~mm})$, these being also the most resistant strawberries to mechanical damage which involves a longer compression and not just mechanical impact. Both the instantaneous and the retarded elastic strain increase with the maturation stages, the highest values being recorded by overripe strawberries (S3 stage) and the lowest by almost ripe ones (S1 stage) which means that fruits resistance decreases during ripening process. According to Chakespari 2010, [11] the retardation time $\left(\lambda_{\text {ret }}\right)$ represents an important factor in fruits storage period and as Burger model predicted the higher retardation time was recorded by the almost ripe strawberries (98.949-140.83 s), the almost ripe Magic variety being characterized by an higher storage time. The absolute average deviation -AAD and the coefficient of determination $-\mathrm{R}^{2}$ represents a measure of how much the Burger model predicted data deviates from the experimental data. 
The ADD values for the Burger model with four Kelvin Voigt elements range between 0.30 and 4.26, whereas the $\mathrm{R}^{2}$ values range between 0.926 and 0.983 . Considering the above mentioned values it seems that Burger model with four Kelvin Voigt elements can be used successfully for the interpretation of strawberries creep curves and to determine the viscoelastic parameters.

Table 3 presents the Pearson correlation of viscoelastic and physicochemical parameters of strawberries. It seems that some viscoelastic parameters are positively correlated with creep strain $(\mathrm{S})$ and area under the curves $(\mathrm{W})$. A significant positive correlation was recorded between the instantaneous elastic strain $\left(\varepsilon_{1}\right)$ and area under the curves $\left(\mathrm{p}<0.01, \mathrm{r}=0.805^{* *}\right)$; another significant positive correlation being between retarded elastic strain $\left(\varepsilon_{2}\right)$ and the creep strain $(\mathrm{p}<0.01, \mathrm{r}=0.827 * *)$. Regarding the chemical composition, moisture content was positively correlated with the soluble substances concentration $(\mathrm{p}<0.05)$, the values of this two parameters increasing during the ripening process. The retarded elastic strain and viscous strain are positively influenced one by the other $(\mathrm{p}<0.05)$.

Table 3

Pearson correlation of viscoelastic and physicochemical parameters of strawberries

\begin{tabular}{|c|c|c|c|c|c|c|c|c|c|c|}
\hline & $\mathbf{S}$ & $\mathbf{W}$ & $\boldsymbol{\varepsilon 1}$ & $\boldsymbol{\varepsilon} 2$ & $\boldsymbol{\varepsilon 3}$ & $\lambda_{\text {ret }}$ & $\mathbf{M}$ & $\mathbf{B}$ & $\mathbf{p H}$ & $\mathbf{T A}$ \\
\hline $\mathrm{S}$ & 1 & $0.989^{* *}$ & $0.740^{*}$ & $0.827^{* *}$ & $0.792^{*}$ & 0.391 & -0.027 & 0.326 & 0.302 & -0.439 \\
\hline $\mathrm{W}$ & & 1 & $0.805^{* *}$ & $0.765^{*}$ & $0.721^{*}$ & 0.332 & -0.027 & 0.345 & 0.394 & -0.504 \\
\hline$\varepsilon_{1}$ & & 1 & 0.244 & 0.356 & 0.244 & -0.281 & 0.031 & 0.575 & -0.529 \\
\hline$\varepsilon_{2}$ & & & & 1 & $0.779^{*}$ & 0.374 & 0.188 & 0.457 & -0.023 & -0.208 \\
\hline$\varepsilon_{3}$ & & & & 1 & 0.160 & 0.210 & 0.385 & 0.129 & -0.333 \\
\hline$\lambda_{\text {ret }}$ & & & & & 1 & -0.529 & -0.322 & -0.397 & 0.370 \\
\hline M & & & & & & 1 & $0.794^{*}$ & 0.230 & -0.355 \\
\hline B & & & & & & & 1 & 0.473 & -0.657 \\
\hline pH & & & & & & &. & 1 & $-0.949^{* *}$ \\
\hline TA & & & & & & & & & 1 \\
\hline
\end{tabular}

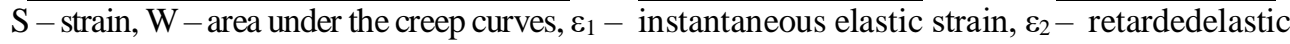
strain, $\varepsilon_{3}-$ viscous strain, $\lambda_{\text {ret }}-$ retardation time; $\mathrm{M}-$ moisture, $\mathrm{B}-$ Brix concentration, TA total acidity.

\section{Principal component analysis (PCA)}

Principal Component Analysis (PCA) carried out on strawberry samples explains all the data variation; first component (PC1) explains $81 \%$ while second one (PC2) explains $19 \%$ of the variance in the obtain data. The results of correlations loadings and scores of PCA are presented in Figure 3 and Figure 4 based on this statistical analysis the strawberry samples are distributed in different quadrants. From PCA score, Figure 3, we can observe that PC1 separates the almost ripe strawberry samples (S1) from the other samples (S2 and S3), while the PC2 separates the samples based on strawberry variety.

In Figure 4 - PCA loadings, the parameters distributed in the center of the ellipse (the instantaneous elastic strain and the viscous strain) have an insignificant influence in samples differentiation, while the parameters from outside ellipse (the creep curve characteristic, retardation time, retarded elastic strain, moisture, $\mathrm{pH}$, Brix concentration and total acidity) present a strong influence in samples differentiation. 


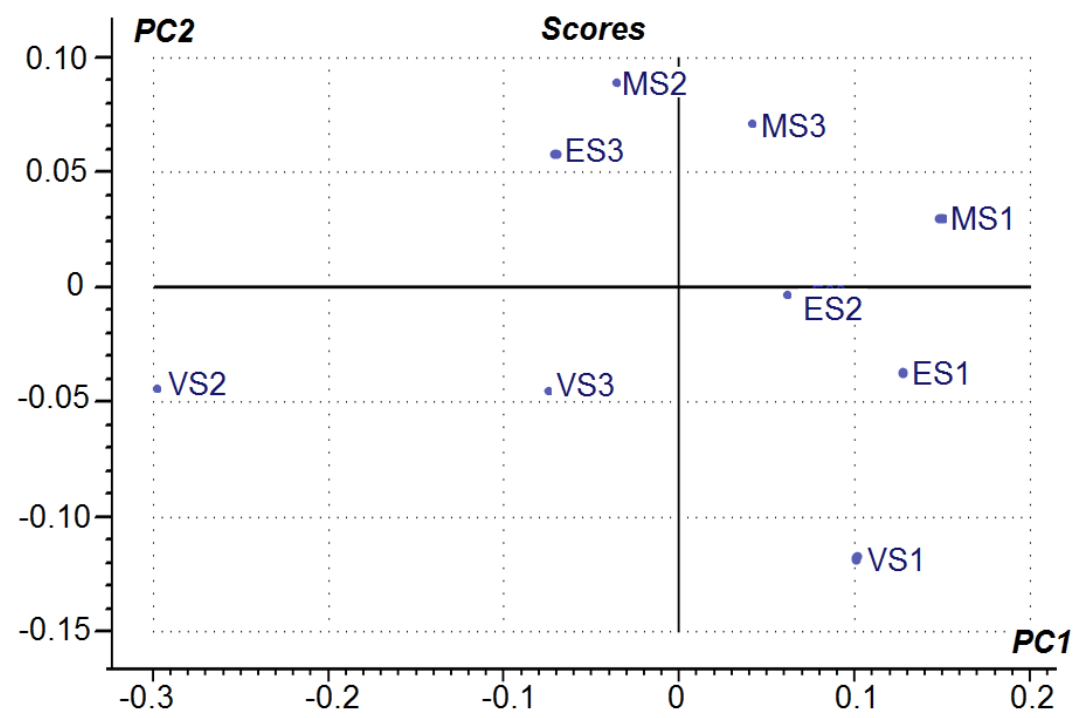

Figure 3. PCA scores of strawberry samples:

M - Magic, E - Elsanta, V - Vibrant, S1 - almost ripe, S2 - ripe, S3 - overripe.

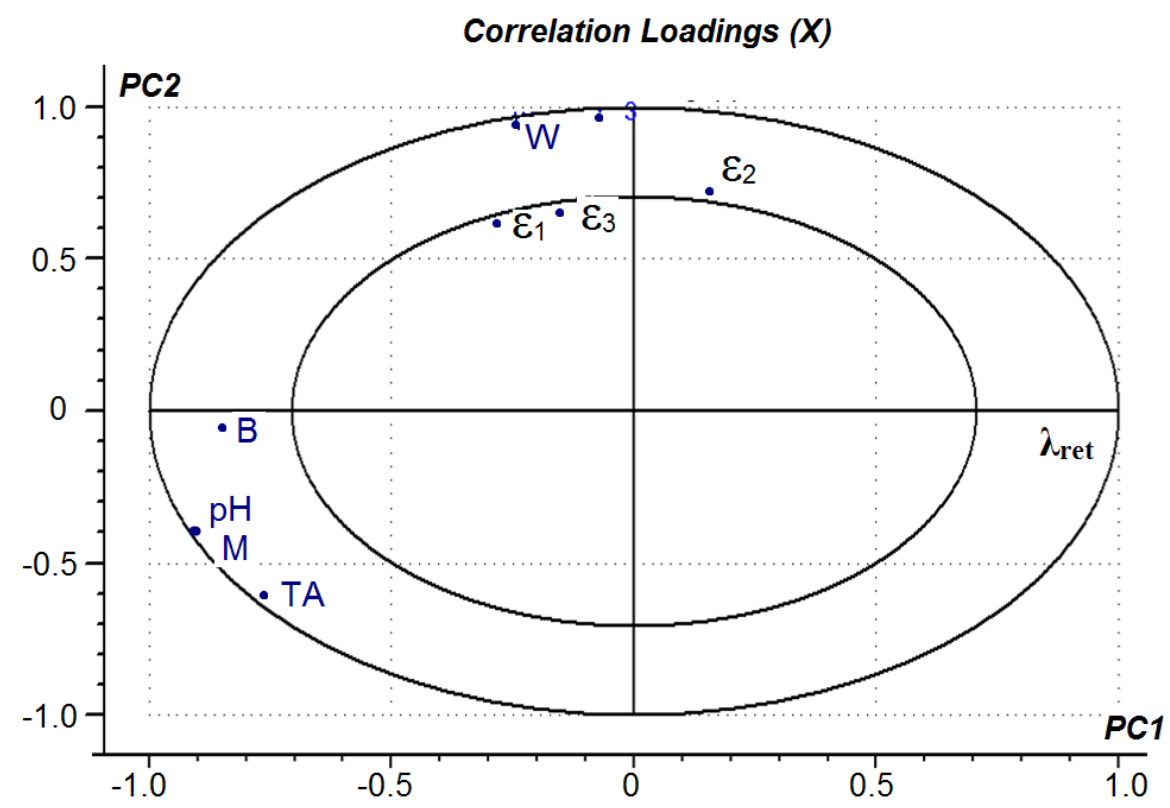

Figure 4. PCA loadings of strawberry samples parameters:

$\mathrm{S}$ - strain, $\mathbf{W}$ - area under the creep curves, $\varepsilon_{1}-$ instantaneous elasticstrain, $\varepsilon_{2}$ - retardedelastic strain, $\varepsilon_{3}-$ viscous strain, $\lambda_{\text {ret }}$-the retardation time; M - moisture, B - Brix concentration, TA -total acidity. 
The Burger model retardation time is strongly correlated with first component (PC1) and consequently with almost ripe strawberry samples, which showed the lowest values of Brix concentration and the highest total acidity and retardation time. The creep strain (S) influences the Magic strawberry projection, this variety being characterized by high values of Burger instantaneous elastic strain.

\section{Conclusions}

The compression creep test conducted in this study highlighted that all strawberries samples presents viscoelastic properties influenced by the variety and by the maturity stages. The strawberries from Vibrant variety have the highest resistance to mechanical impact and also a high mechanical resistance to compression due to the fact that showed the lowest values of instantaneous and retarded elastic strain. Keeping into account the $\mathrm{R}^{2}$ and ADD values, the mechanical Burger model with four Kelvin Voigt elements can be successful used to determine the viscoelastic properties of strawberries samples such as instantaneous elastic strain, retarded elastic strain or retardation time. The PCA statistical analysis revealed that creep curves characteristic and Burger viscoelastic properties have a great impact in strawberry samples projection based on variety and maturity stages.

Acknowledgement. This work was supported by "DECIDE Dezvoltare prin educație antreprenorială și cercetare inovativă doctorală și postdoctorală”, Cod proiect POCU/380/6/13/125031, proiect cofinanțat din Fondul Social European prin Programul Operațional Capital Uman 2014 - 2020"

\section{References}

1. López-Valencia D., Sánchez-Gómez M., Acuña-Caita J. F., Fischer G. (2018), Physicochemical properties of seven outstanding strawberry (Fragaria $\mathrm{X}$ ananassaDuch.) varieties cultivated in Cundinamarca (Colombia) during maturation, CorpoicaCiencia y TecnologíaAgropecuaria, 19(1), pp. 147-162.

2. Zeliou K., Papasotiropoulos V., Manoussopoulos Y., Lamari F. N. (2018), Physical and chemical quality characteristics and antioxidant properties of strawberry cultivars (Fragariax ananassaDuch.) in Greece: assessment of their sensory impact, Journal of the Science of Food and Agriculture, 98(11), pp. 4065-4073.

3. Kim S. K., Bae R.N., Na H., Dal Ko K., Chun C. (2013), Changes in physicochemical characteristics during fruit development in June-bearing strawberry cultivars, Horticulture, Environment, and Biotechnology, 54(1), pp. 44-51.

4. Azodanlou R., Darbellay C., Luisier J.L., Villettaz J. C., Amadò R. (2004), Changes in flavour and texture during the ripening of strawberries, European Food Research and Technology, 218(2), pp. 167-172.

5. Jia H., Wang Y., Sun M., Li B., Han Y., Zhao Y., Jia W. (2013), Sucrose functions as a signal involved in the regulation of strawberry fruit development and ripening, New Phytologist, 198(2), pp. 453-465. 
6. Temocico G., Sturzeanu M., Ion V. (2017), Choice of strawberry varieties by the Romanian growers, Scientific Papers: Management, Economic Engineering in Agriculture \& Rural Development, pp. 17(1).

7. Døving A., Måge F., Vestrheim S. (2005), Methods for testing strawberry fruit firmness: a review, Small Fruits Review, 4(2), pp. 11-34.

8. Duprat F., Grotte M. G., Pietri E., Studman C. J. (1995), A multi-purpose firmness tester for fruits and vegetables, Computers and electronics in agriculture, 12(3), 211-223.

9. Sirisomboon P., \& Posom J. (2018), A new creep model for studying the non-linear viscoelastic behavior of cooked white, brown and germinated brown Thai jasmine rice by large deformation testing, Heliyon, 4(8), e00745.

10. Lazaridou A., Vouris D.G., Zoumpoulakis P., Biliaderis C.G. (2018), Physicochemical properties of jet milled wheat flours and doughs, Food hydrocolloids, 80, pp. 111-121.

11. Chakespari A. G., Rajabipour, A., Mobli H. (2010), Anisotropic relaxation and creep properties of apple (cv. ShafiAbadi and GolabKohanz), Advanced Journal of Food Science and Technology, 2, pp. 200-205.

12. Dzadz Ł., Markowski M., Sadowski P., Jakóbczak A., Janulin M. (2015), Creep and recovery characteristics of chicken meat Frankfurters, Journal of Agricultural Science and Technology, 17(4), pp. 827-835.

13. Álvarez M.D., Canet W., Cuesta F., Lamua M. (1998), Viscoelastic characterization of solid foods from creep compliance data: application to potato tissues, ZeitschriftfürLebensmitteluntersuchung und-Forschung A, 207(5), pp. 356362.

14. Mohammed M. A. P., Tarleton E., Charalambides M. N., Williams J. G. (2013), Mechanical characterization and micromechanical modeling of bread dough, Journal of Rheology, 57(1), pp. 249-272.

15. Nussinovitch A.M. M. A., Ak M. M., Normand M. D., Peleg M. (1990), Characterization of gellan gels by uniaxial compression, stress relaxation and creep, Journal of Texture Studies, 21(1), pp. 37-50.

16. Pădureț S., Oroian M., Gutt G., Amariei S. (2017), Evaluation of strawberry texture in close relation with their anisotropy, International Journal of Food Properties, 20(2), pp. 247-259.

17. ISO 1842:1991, Fruit and vegetable products - Determination of $\mathrm{pH}$

18. ISO 750:1998, Fruit and vegetable products determination of titratable acidity

19. Paduret S., \& Gutt G., (2016), The Use of Texture Destructive Methods to Assess the State of Pork Freshness, Food and Environment Safety Journal, pp. 14(2).

20. Bourne C., M., (2002), Food Texture and Viscosity: Concept and Measurement, An Elsevier Science Imprint, London.

21. Xu Y. L., Xiong S. B., Li Y. B., Zhao S. M. (2008), Study on creep properties of indica rice gel, Journal of Food Engineering, 86(1), pp. 10-16.

22. Sahin S., \& Sumnu S. G. (2006), Physical properties of foods, Springer Science \& Business Media

23. Moghaddam M. G., Ahmad F. B. H., Basri M., Rahman M. B. A., (2010), Artificial neural network modeling studies to predict the yield of enzymatic synthesis of betulinic acid ester. Electronic Journal of Biotechnology, 13(3), pp. 3-4

24. Oroian M., Paduret S., Amariei S., Gutt G. (2016), Chemical composition and temperature influence on honey texture properties, Journal of food science and technology, 53(1), pp. 431-440.

25. Nunes M. C. N., Brecht J. K., Morais A. M., Sargent S. A. (2006), Physicochemical changes during strawberry development in the field compared with those that occur in 
harvested fruit during storage, Journal of the Science of Food and Agriculture, 86(2), pp. $180-190$.

26. Khan M. N., Sarwar A., Bhutto S., Wahab M. F. (2010), Physicochemical characterization of the strawberry samples on regional basis using multivariate analysis, International Journal of Food Properties, 13(4), pp. 789-799.

27. Vergara M., Vargas J., Acuña J. (2018), Physicochemical characteristics of strawberry (Fragaria $\chi$ ananassaDuch.) fruits from four production zones in Cundinamarca, Colombia. Agronomía Colombiana, 36(3), pp. 227-236

28. da Silva Pinto M., Lajolo F. M., Genovese M. I. (2008), Bioactive compounds and quantification of total ellagic acid in strawberries (Fragaria $\mathrm{x}$ ananassaDuch.), Food Chemistry, 107(4), pp. 1629-1635. 